\title{
Design and Implementation of Cuk Converter for Power Factor Correction of PMBLDC Motor Drive
}

\author{
Amit Tripathi, Anurag Verma
}

\begin{abstract}
The present project relates to designing of a cuk converter for improving power factor at AC main supply for the PMBLDC motor. In the work an electronic communication technique is used as the motor requires a distortion less controlled $D C$ voltage served to Voltage Source Inverter. The main reason to implement the project is to achieve betterment in the performance of the motor. The work overcomes the problems associated with less power factor of AC main supply. The project helps in eliminating current harmonics generally appears at source input supply by employing a closed loop procedure. A converter called cuk converter and DBR are used for $D C$ to $D C$ and for $A C$ to $D C$ conversion respectively. The analysis of power quality is observed by using a software MATLAB/Simulink and implementation on hardware is also done to verify the analysis.
\end{abstract}

Index Terms-Permanent Magnet Brush Less DC (PMBLDC motor), Cuk converter, V.S.I, Diode Bridge Rectifier (DBR).

\section{INTRODUCTION}

Today brushless DC motor is used in extensive variety of applications such as railway fans, medical appliances etc., Generally a BLDC motor is a synchronous motor whose rotor is a permanent magnet type rotor and stator has phase windings. The motor works only with closed loop system due to electronic communication. Electronic communication enables decoding of triggering 'Voltage Source Inverter' gate pulse after recognizing the position of rotor by using an effect of hall sensor. This technique is used to lessen the noise and reduce the requirement of maintenance of machine. Consequently, the motor carries many gains because it is used in variety of applications. The BLDC motor is a $3 \phi$ motor, $1 \Phi$ AC power supply is applied to the complete projected system, the load (a BLDC motor), a control unit, power modulator block, sensing unit as represented in Figure 1 .

A $3 \phi$ VSI, a diode bridge type rectifier, and a DC to DC converter in combination make a modulator. The rotor is covered and its position can be identified by the electronic communication and that feature is provided in the sensing unit. The sensors which have been used in the system are

Revised Version Manuscript Received on 10 September, 2019.

AmitTripathi, Department of Electronics \& Communication Engineering, Noida Institute of Engineering and Technology, UttarPradesh, India. (Email: researchnietip@gmail.com)

AnuragVerma, Department of Electronics \& Communication Engineering, Noida Institute of Engineering and Technology, UttarPradesh, India. (Email: researchnietip@gmail.com) where a machine (motor) with synchronous speed is needed.

'Hall Effect' sensors. The signal is another time decoded and applied to the VSI.

A DC to DC converter is present in the modulator which is specifically here a cuk type converter which is chosen for lessening the harmonics value at main supply and also for reducing the irregular energization of a capacitor of DC link. Hereafter the aim of betterment in correction of power factor (PF) improvement is also achieved in converter's closed loop. Cuk type converter provides constant input and output currents and has extensive range of voltage, so it has been used here. As its name is cuk, the converter implement both the functions of buck converter (stepping down the voltage value) and boost converter (stepping up the voltage) according to the setting of duty cycle.

The construction of cuk type converter includes two inductors and two capacitors for storing the energy therefore it is a converter circuit with order 4 . As above said the converter uses closed loop operations therefore power quality can be improved according to the standards of IEC61000-3-2. Improvement in power factor would apparently enhance the system's use. When the value of power factor is low, that means the system have been used in ineffective manner and the motor will generate back emf conflicting to the applied voltage, resulting in decrease in current value and increase in voltage value which further leads to lower value of power factor (PF) this is why we look forward to a closed loop control unit for power factor correction.

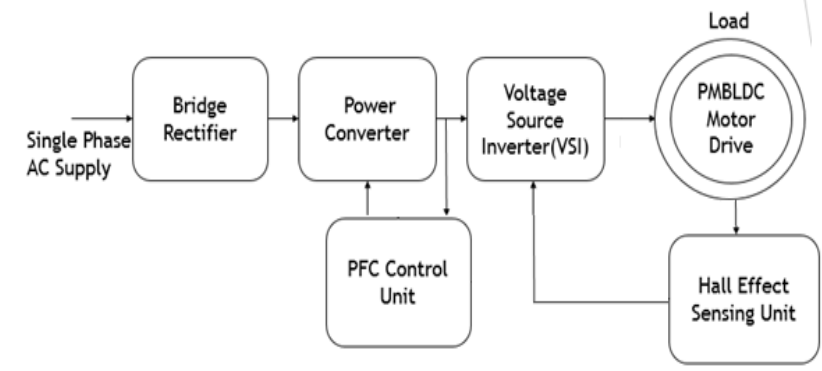

Figure 1: Block diagram of proposed system

There are 3 modes for a 'Cuk' converter to operate are: In $1^{\text {st }}$ mode of operation, the switch represented as ' $\mathrm{SW}$ ' is turned $\mathrm{ON}$ the current flowing through inductor increases and then passes through the switch. The voltage which is present across the connected capacitor would reverse the diode and then capacitor ' $\mathrm{C} 1$ ' of the converter gets discharged or pass 


\section{DESIGN AND IMPLEMENTATION OF CUK CONVERTER FOR POWER FACTOR CORRECTION OF PMBLDC MOTOR DRIVE}

its energy to the connected load via a conducting path. From Figure $3 \mathrm{a}$ we can say that in this mode the polarity of output voltage and dsirection of current gets reversed.

In $2^{\text {nd }}$ mode of operation the switch represented as ' $\mathrm{S}$ ' is switched off. The current of inductor i.e. iL1 starts decreasing via a capacitor $\mathrm{C} 1$ and diode $\mathrm{D}$ and the capacitor starts charging from the applied voltage 'Vs'. Similar to the $1^{\text {st }}$ mode of operation in this also the output polarity is reversed from previous one.

Both diode D and switch are kept off position. The energy stored the inductor charges the capacitor $\mathrm{C} 2$ as illustrated in Figure 3c.

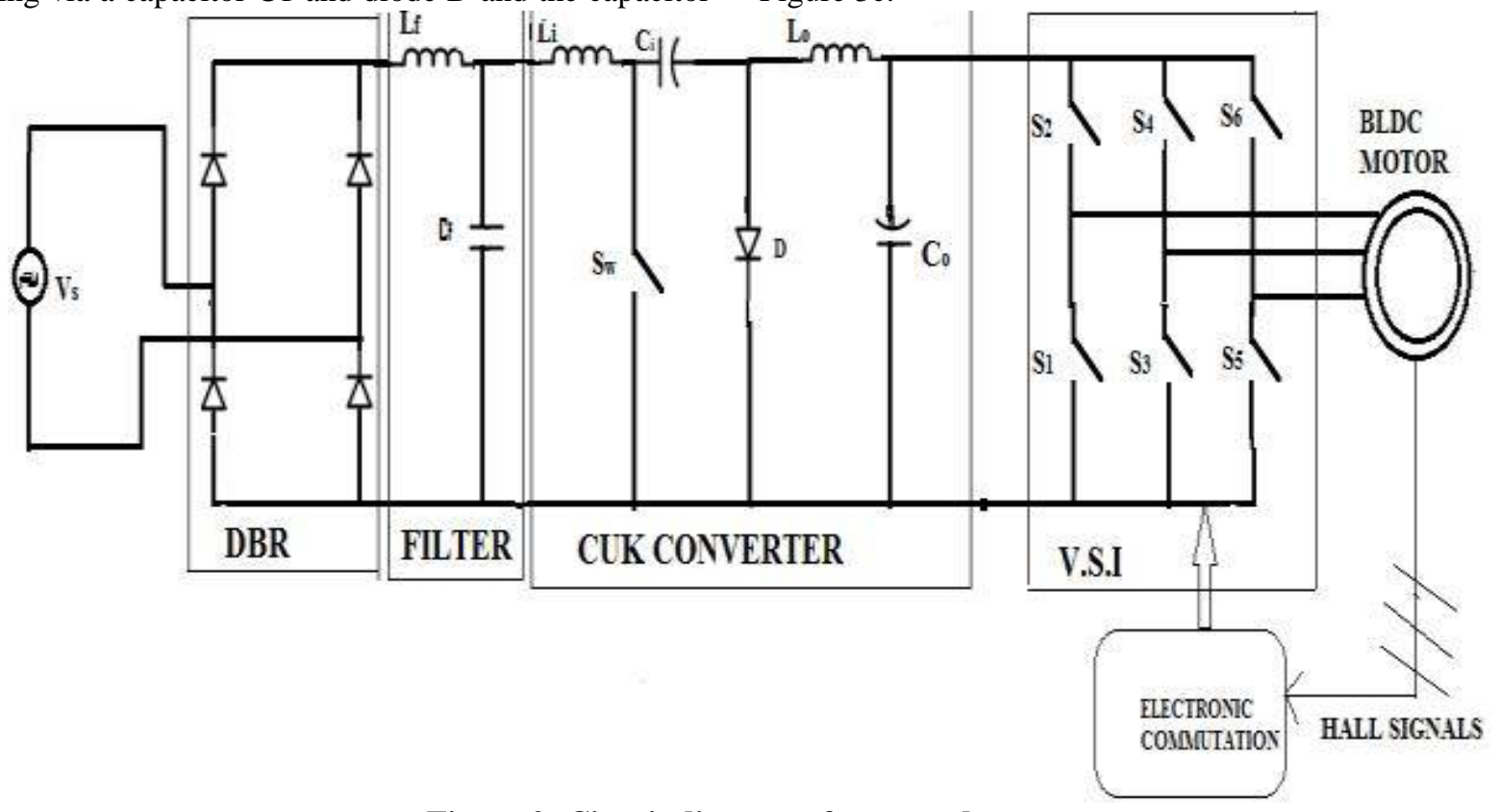

Figure 2: Circuit diagram of proposed system

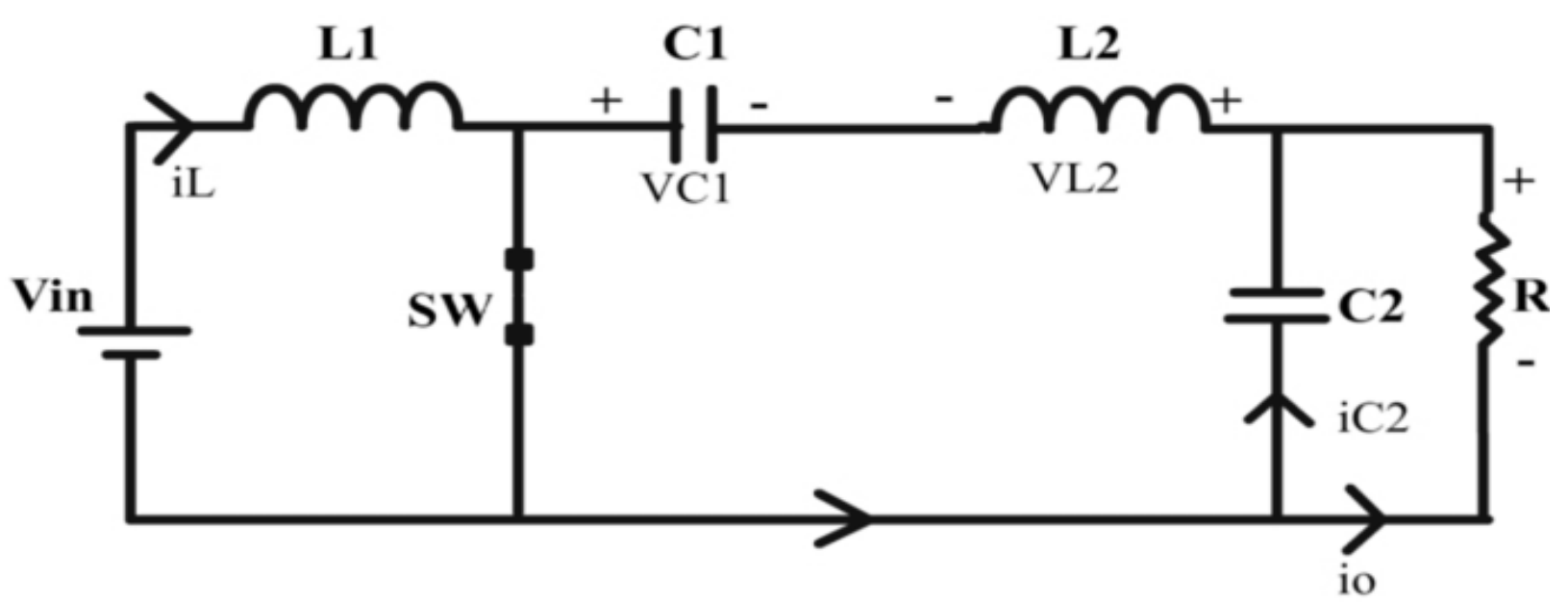

Figure 3-a $1^{\text {st }}$ mode of operation

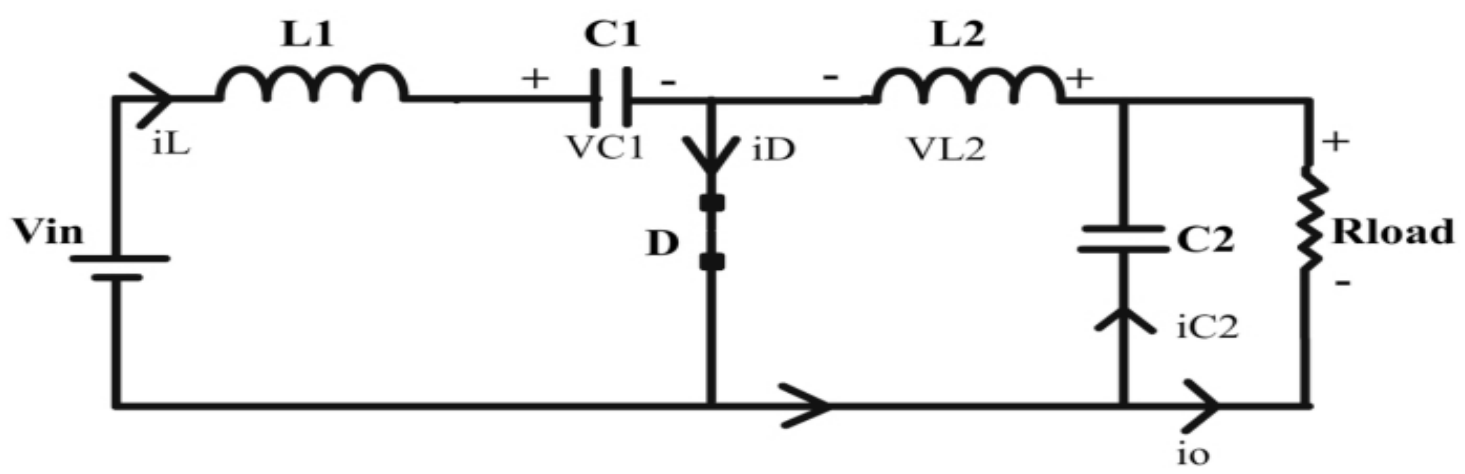

Figure 3-b $2^{\text {nd }}$ mode of operation

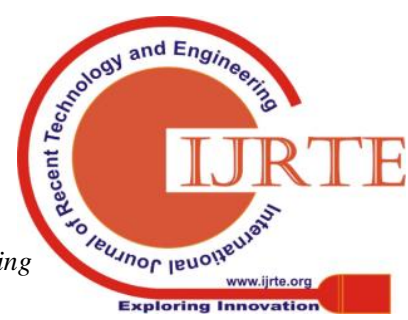




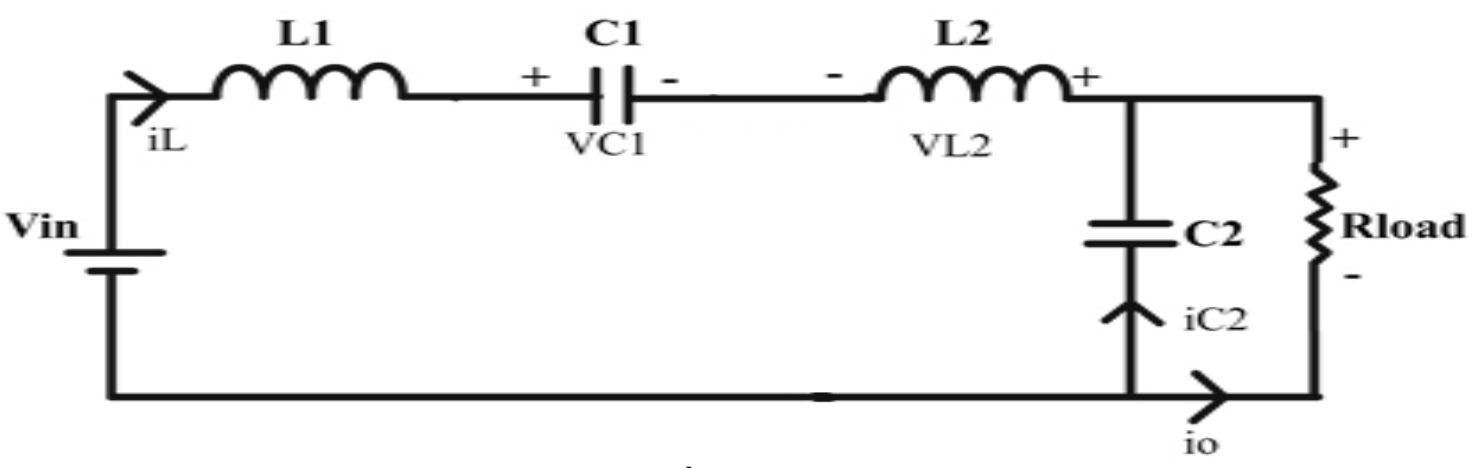

Figure $3 c 3^{\text {rd }}$ mode of operation

\section{DESIGN OF CUK CONVERTER}

Average value of input voltage:

$$
V_{i n}=\frac{2 \sqrt{2} V_{S}}{\pi}
$$

The Duty cycle Ratio 'D' can be written as:

$$
\frac{V_{O}}{V_{S}}=\frac{D}{1-D}
$$

Input inductance value:

$$
L_{i}=\frac{D V_{\text {in }}}{\Delta L_{i} f_{s}}
$$

Output inductance:

$$
L_{o}=\frac{(1-D) V_{d c}}{\Delta I_{L o} f_{S}}
$$

Middle capacitor's capacitance:

$$
C_{i}=\frac{D I_{d c}}{\Delta V_{c 1} f_{s}}
$$

Capacitance value of DC-Link capacitor:

$$
C_{d}=\frac{I_{d c}}{\omega \Delta V_{c d}}
$$

Resistance of R- Load:

$$
R_{L}=\frac{V_{d c}^{2}}{P_{i}}
$$

Table 1: Design values of cuk converter

\begin{tabular}{|l|l|}
\hline \multicolumn{1}{|c|}{ Parameter } & \multicolumn{1}{c|}{ Rating } \\
\hline Supply voltage $\left(\mathrm{V}_{\mathrm{S}}\right)$ & $48 \mathrm{~V}$ \\
\hline DC link voltage $\left(\mathrm{V}_{\mathrm{dc}}\right)$ & $24 \mathrm{~V}$ \\
\hline Switching frequency $\left(\mathrm{f}_{\mathrm{s}}\right)$ & $40 \mathrm{kHz}$ \\
\hline Output current $\left(\mathrm{I}_{\mathrm{o}}\right)$ & $4.166 \mathrm{~A}$ \\
\hline Input inductor current ripple $\left(\mathrm{I}_{\mathrm{Li}}\right)$ & $2.15 \mathrm{~A}$ \\
\hline Output inductor current ripple $\left(\mathrm{I}_{\mathrm{LO}}\right)$ & $50 \%$ of $\mathrm{I}_{\mathrm{O}}$ \\
\hline Intermediate capacitor voltage ripple $\left(\mathrm{V}_{\mathrm{ci}}\right)$ & $3.5 \%$ of $\mathrm{V}_{\mathrm{dc}}$ \\
\hline Output capacitor voltage ripple $\left(\mathrm{V}_{\mathrm{cd}}\right)$ & $1.14 \%$ of $\mathrm{V}_{\mathrm{dc}}$ \\
\hline
\end{tabular}

Table 2: Cuk converter design specification

\begin{tabular}{|l|l|}
\hline \multicolumn{1}{|c|}{ Parameter } & \multicolumn{1}{c|}{ Specifications } \\
\hline Supply voltage $\left(\mathrm{V}_{\mathrm{S}}\right)$ & $48 \mathrm{~V}$ \\
\hline DC link voltage $\left(\mathrm{V}_{\mathrm{dc}}\right)$ & $24 \mathrm{~V}$ \\
\hline Switching frequency $\left(\mathrm{f}_{\mathrm{S}}\right)$ & $40 \mathrm{KHZ}$ \\
\hline Inductor $\left(\mathrm{L}_{\mathrm{i}}\right)$ & $1 \mathrm{mH}$ \\
\hline Capacitor $\left(\mathrm{C}_{\mathrm{i}}\right)$ & $45 \mu \mathrm{F}$ \\
\hline Inductor $\left(\mathrm{L}_{0}\right)$ & $185 \mu \mathrm{H}$ \\
\hline Capacitor $\left(\mathrm{C}_{0}\right)$ & $6000 \mu \mathrm{F}$ \\
\hline
\end{tabular}

III. MATLAB SIMULINK \& RESULTS

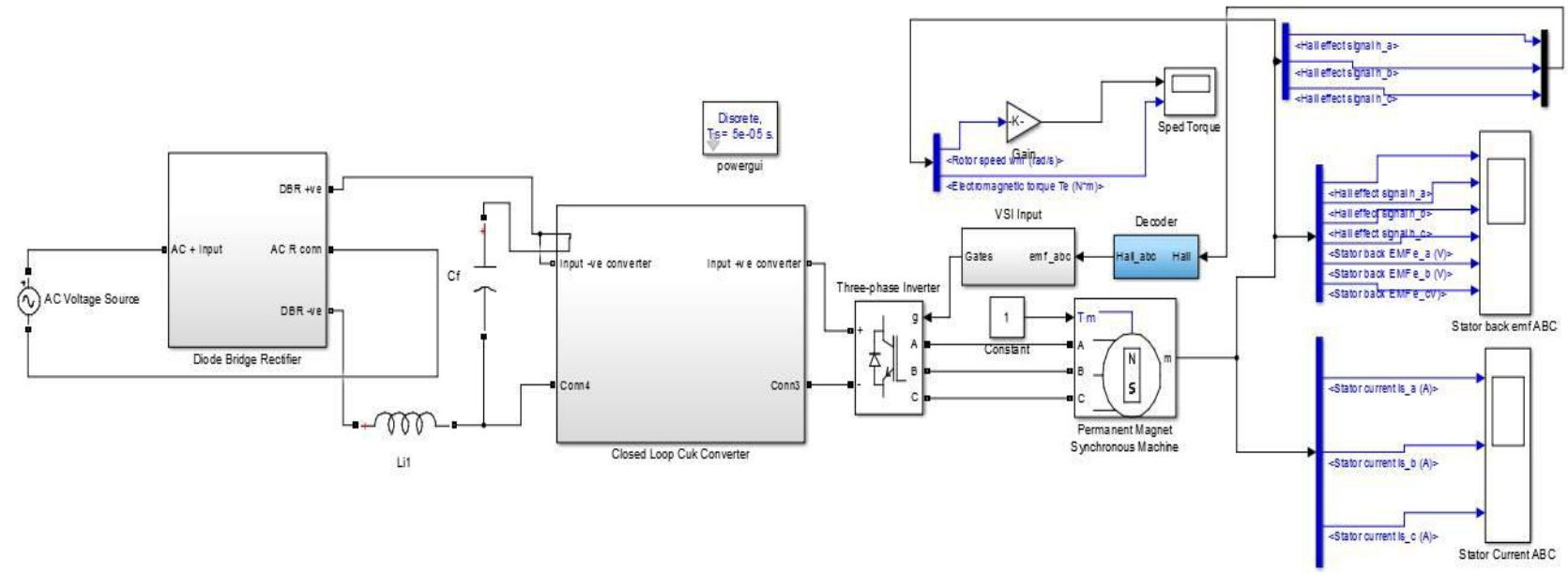

Figure 4 Closed Loop Simulation of projected system

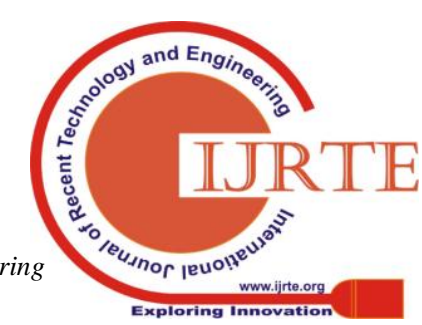




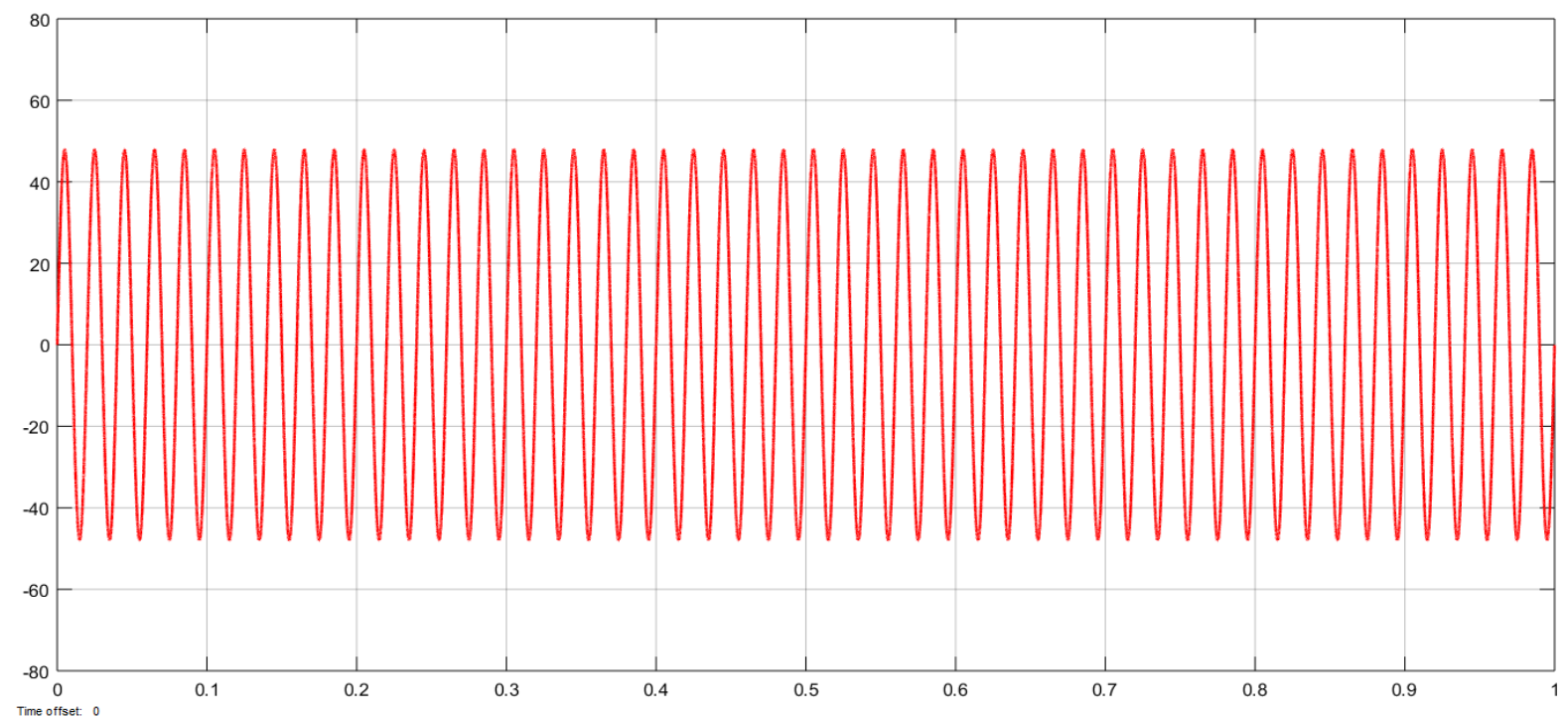

Figure 5 AC input voltage

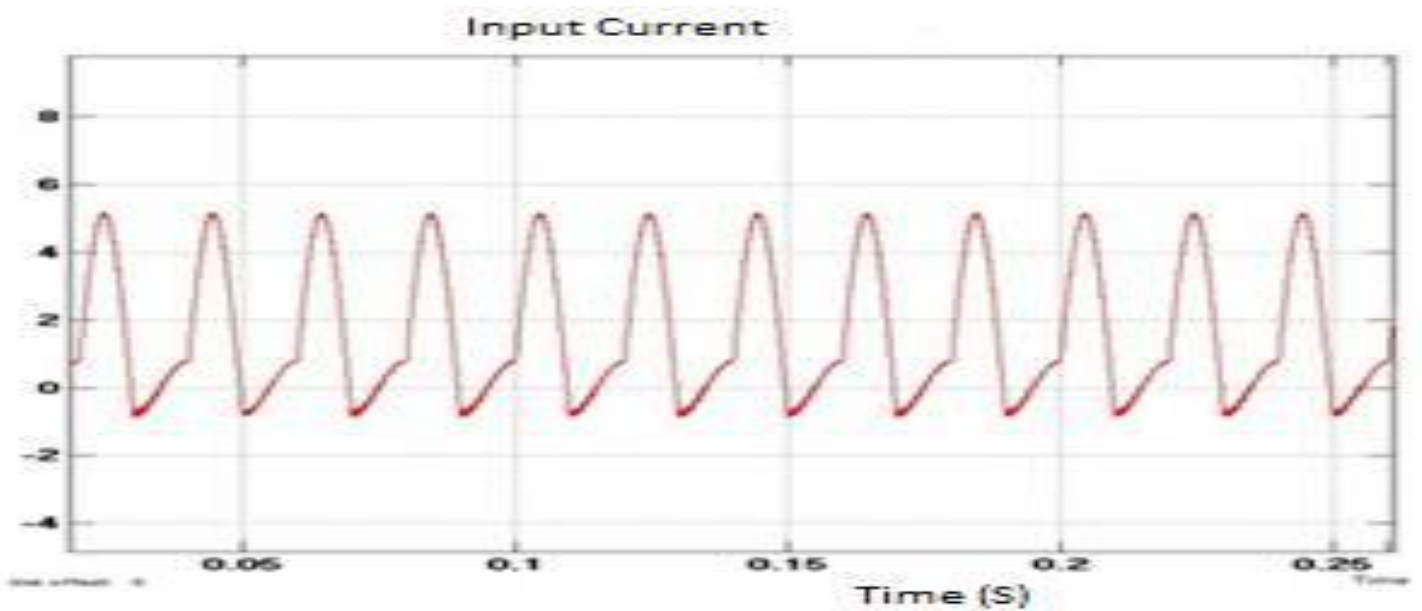

Figure 6 Waveform of Input current

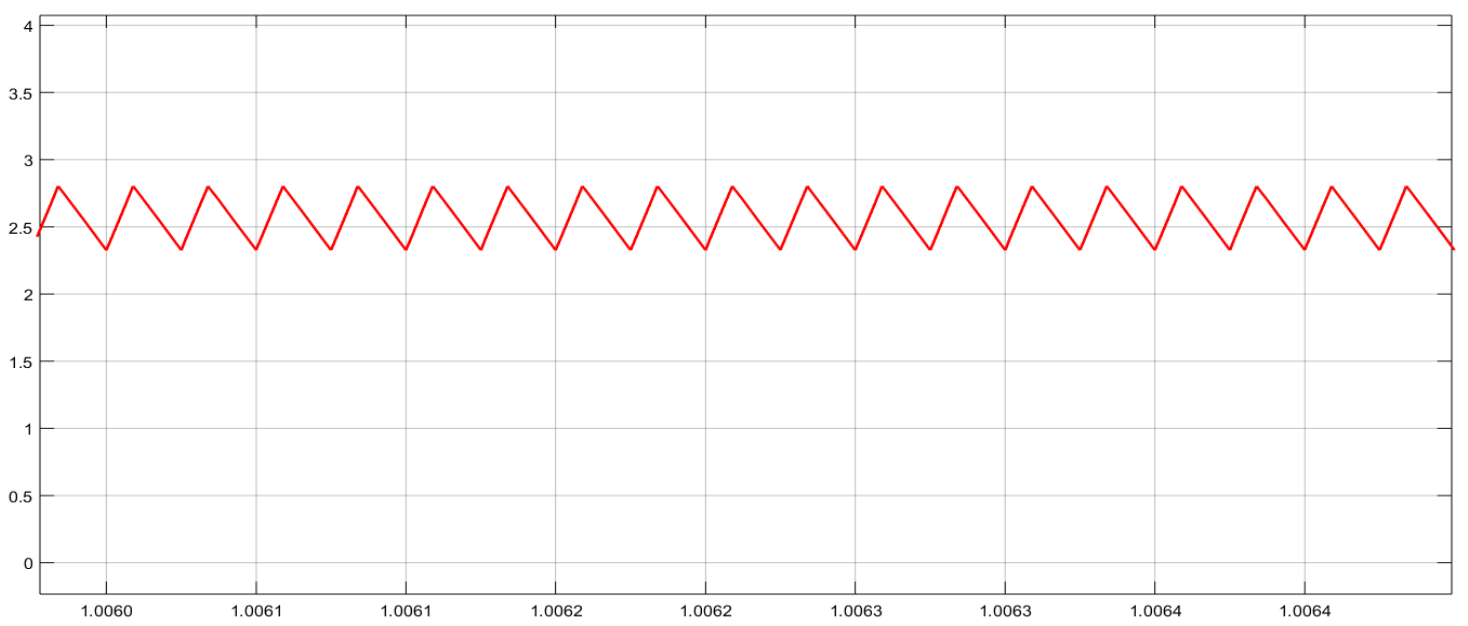

Figure 7 Waveform for Input Inductor current

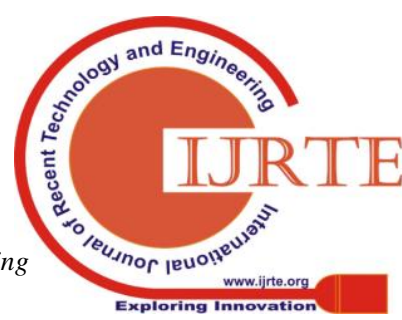




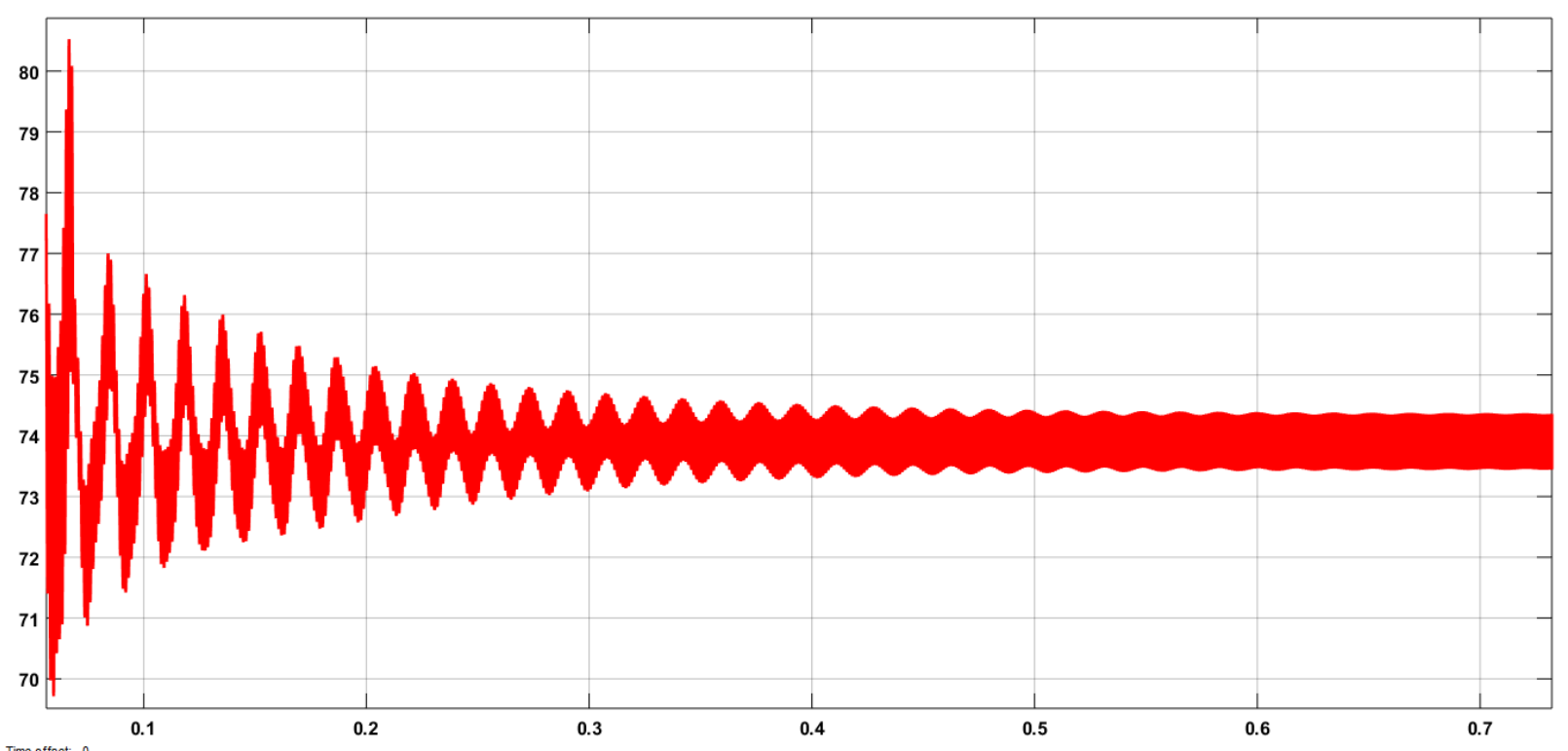

Figure 8 Intermediate Capacitor voltage

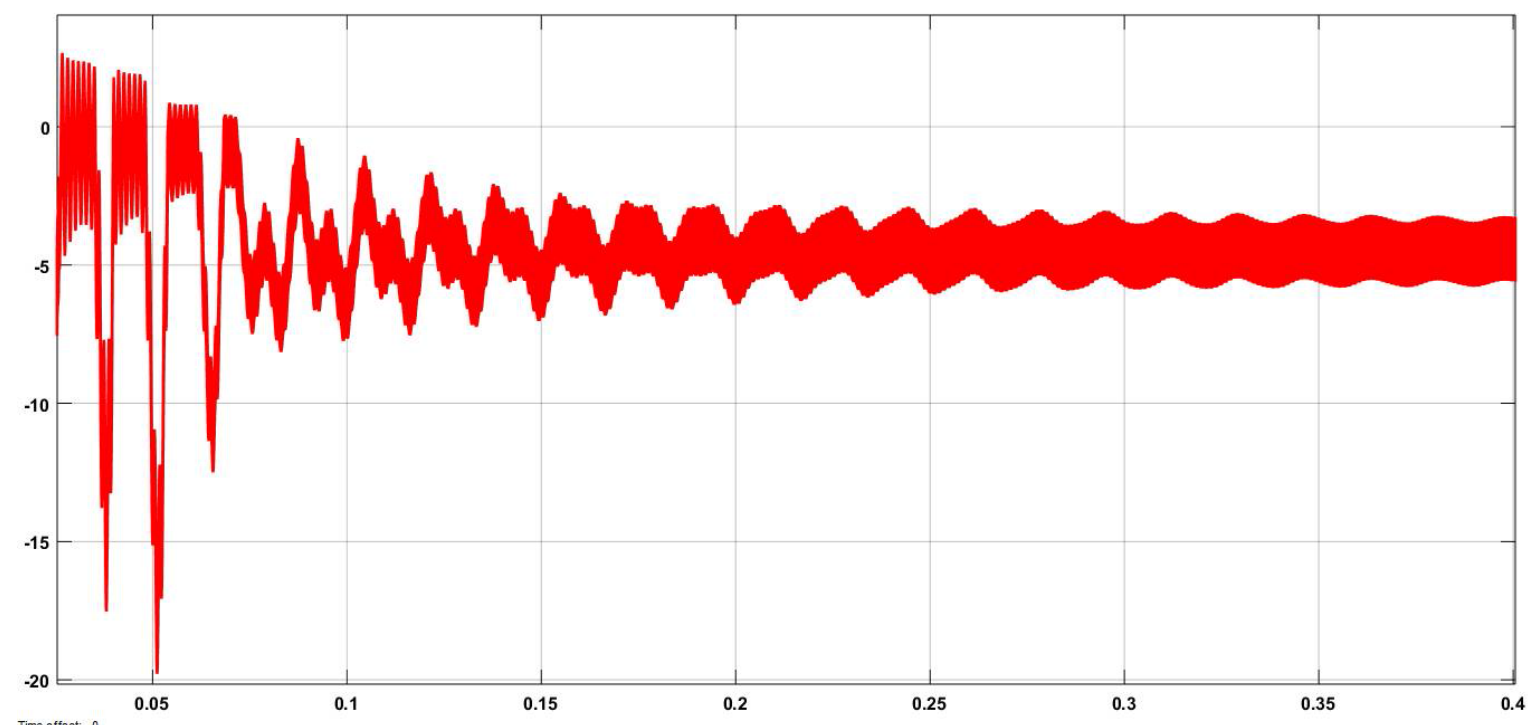

Figure 9 Output Inductor current waveform

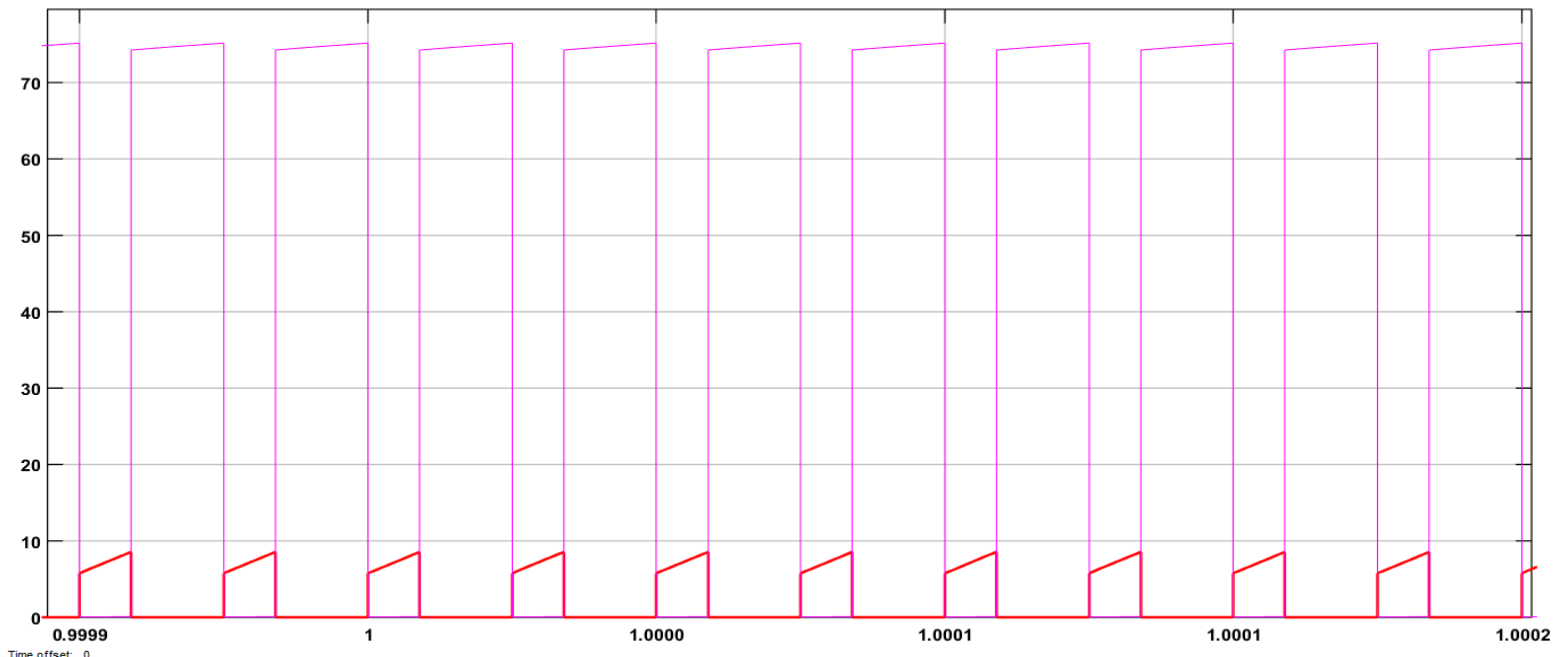

Figure 10 Switch Voltage and Current

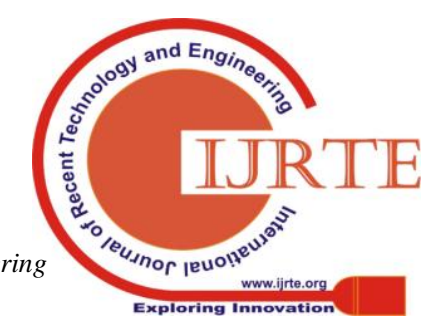




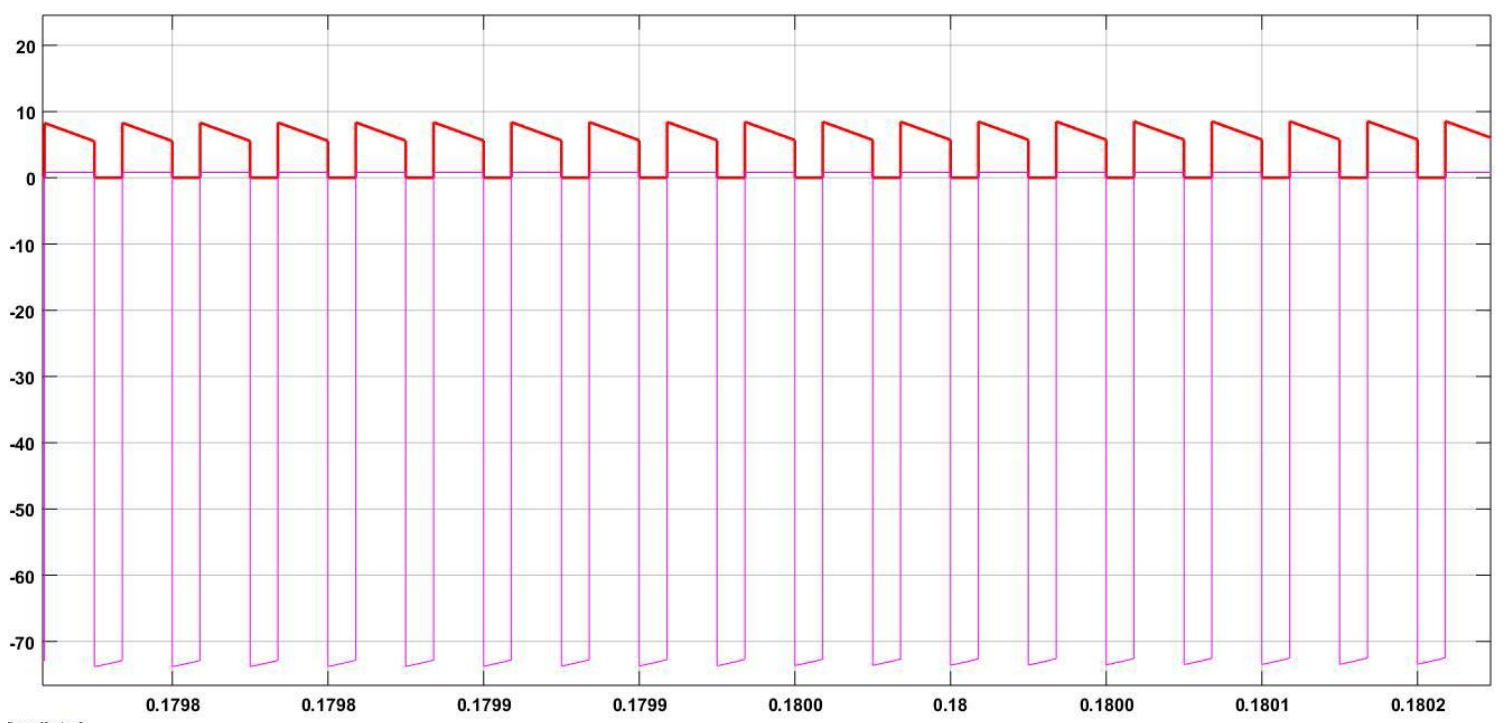

Figure 11 Diode Voltage and Current

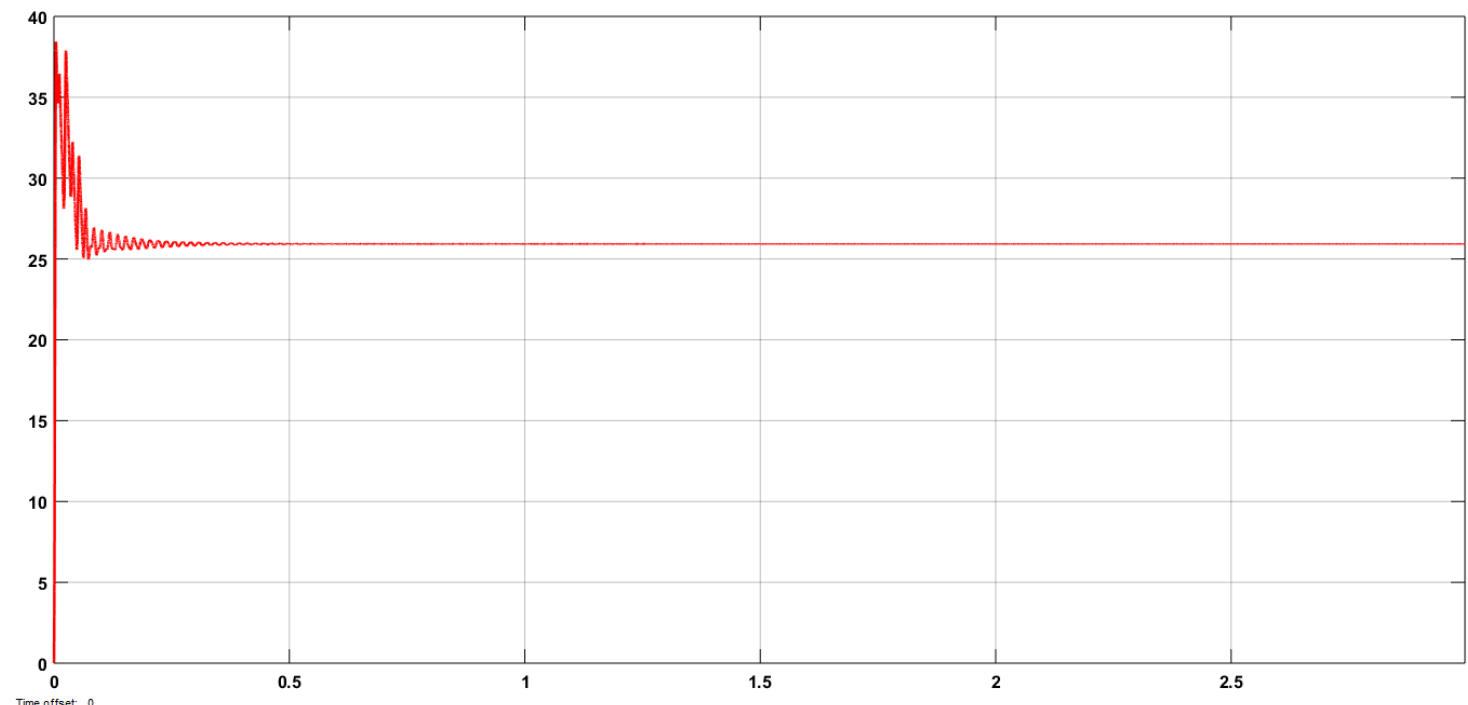

Figure 12 DC Link - Output Voltage
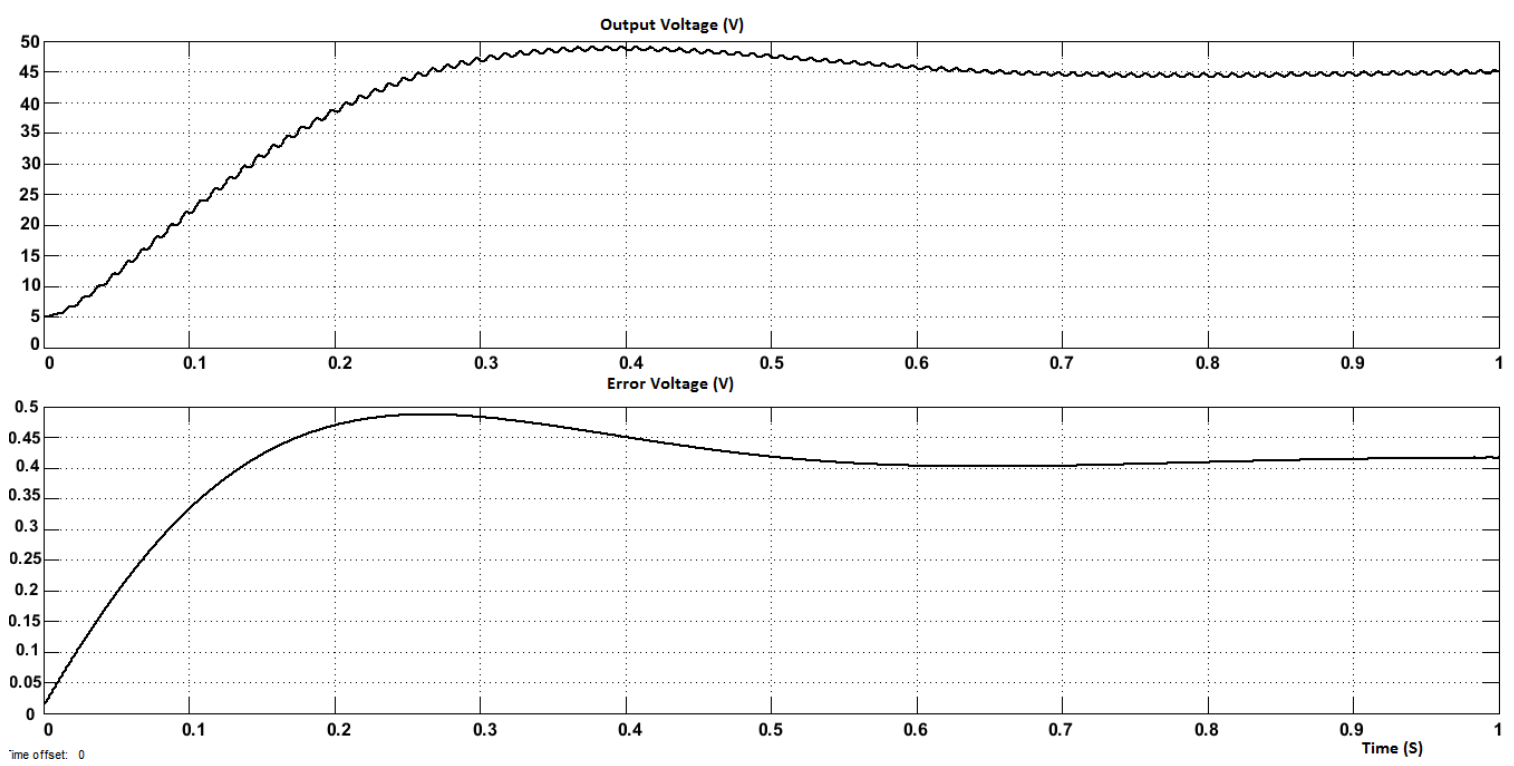

Figure 13 Closed Loop DC Voltage

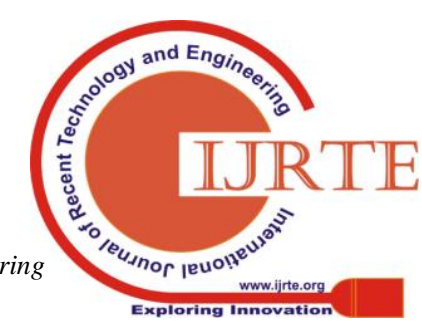


A MATLAB/ Simulink software is used to implement the system for PMDC. Firstly the simulation for 'cuk converter' has been completed by getting the values of different variables by their formulas. Obtained value of power ' $\mathrm{P}$ ' is $120 \mathrm{~W}$ rating of the converter as given in Table 1 . Table 2 contains consistent values of every value. From Figure 4 we can see the combination of Cuk converter, DBR and AC power supply voltage. The strategy uses a fourier block part to observe the supply power factor and the supply angle is 25.69 degrees. By the implementation a power factor in order of 0.91 is gained. A Figure 4 the graph of AC supply voltage. Likewise the waveform of input current having a value of 1.45Amps is given in Figure 6. The current flowing through input inductor is in an average value of current is 2.5 amperes which is shown in Figure 7. Because the capacity to store energy of the intermediate capacitor is extreme, thus the value of voltage across it is 72 volts, can be seen in Figure 8. Charging/Discharging of elements can be seen in the graph. Figure 9 illustrates the waveform of low value currents carried by the output inductors.
The behaviour of voltage across switch and current flowing through it, is also observed to get the knowledge about suitable MOSFET switch, and the graph for this is shown in Figure 10. Correspondingly, Figure 11 represents the graph for the voltage and current at diode. We can observe the output voltage in Figure 12 for the cuk converter which is an open loop converter. From Figure 13 it is observed that after the application of a control unit with the 'cuk' converter the error coming out in the voltage settles in time after 0.6 secs. By which we get a constant value of output DC voltage. In order to get the sequence of switching, the decoder would detect the Hall Effect for $50 \mathrm{~Hz}$ frequency line. The tabular column represents the order of switching for the voltage source inverter with the phase shift is sixty degrees. $50 \mathrm{~Hz}$ line frequency is equivalent .02 secs time period (in one cycle), each and every switch should change its state 2 times on/off. By Figure 15 we can see that the generated back emf for the load motor is trapezoidal. The input is given to the inverter after sensing the Hall Effect by the decoder and the pulse is shown in Figure 14.

TABLE 3: Switching sequence of VSI

\begin{tabular}{|c|c|c|c|c|c|c|}
\hline \multirow{2}{*}{$\Theta($ in degrees) } & \multicolumn{7}{|c|}{ Switching States } \\
\cline { 2 - 7 } & $S_{1}$ & $s_{2}$ & $s_{3}$ & $s_{4}$ & $s_{5}$ & $s_{6}$ \\
\hline $0-60$ & 1 & 0 & 0 & 0 & 0 & 1 \\
\hline $60-120$ & 0 & 1 & 1 & 0 & 0 & 0 \\
\hline $120-180$ & 0 & 0 & 1 & 0 & 0 & 1 \\
\hline $180-240$ & 0 & 0 & 0 & 1 & 1 & 0 \\
\hline $240-300$ & 1 & 0 & 0 & 1 & 0 & 0 \\
\hline $300-360$ & 0 & 1 & 0 & 0 & 1 & 0 \\
\hline
\end{tabular}

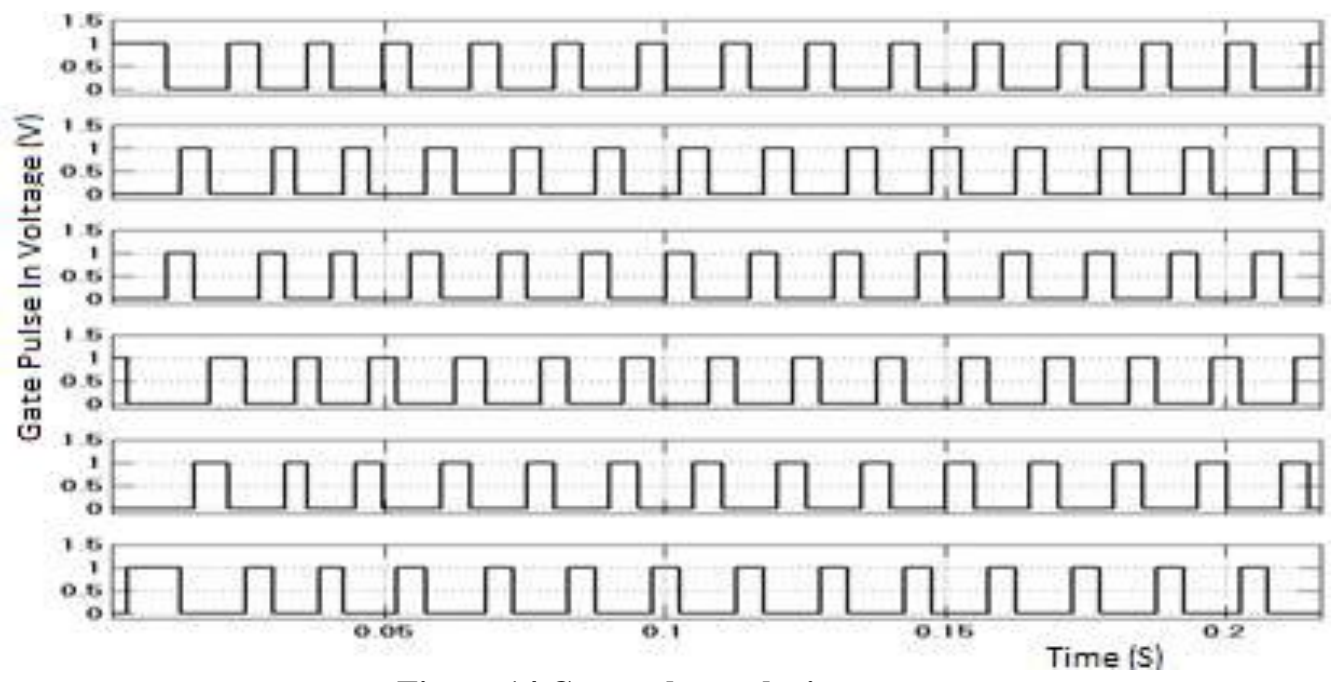

Figure 14 Gate pulse to the inverter 


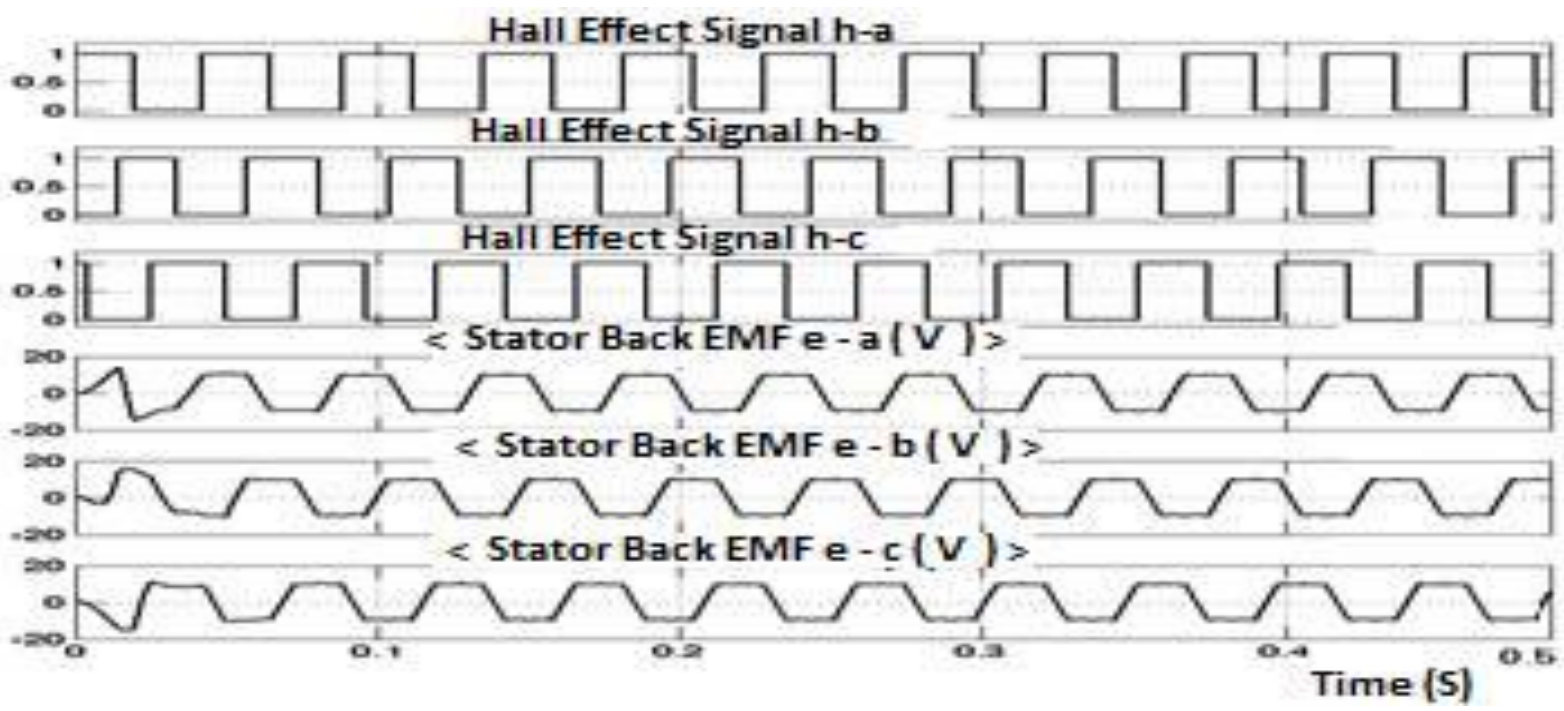

Figure 15 Hall Effect signals and Back EMF

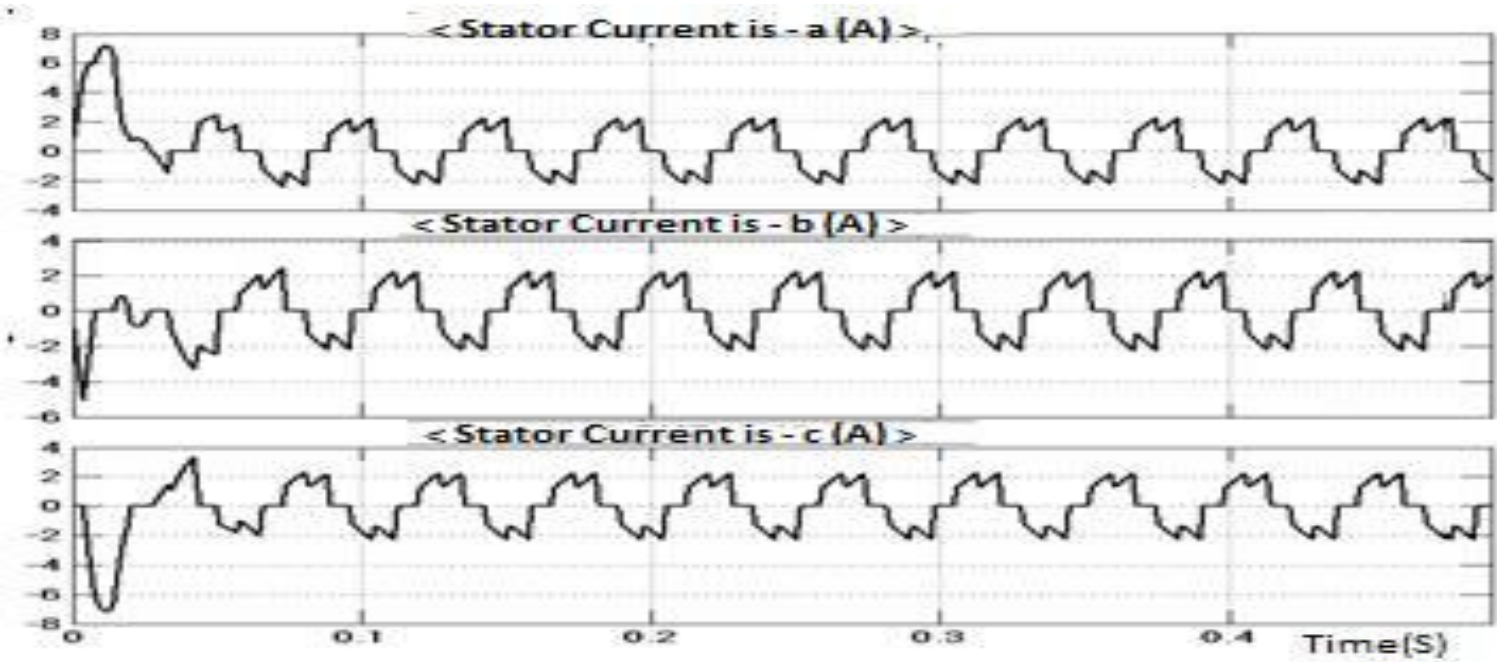

Figure 16 Stator Current

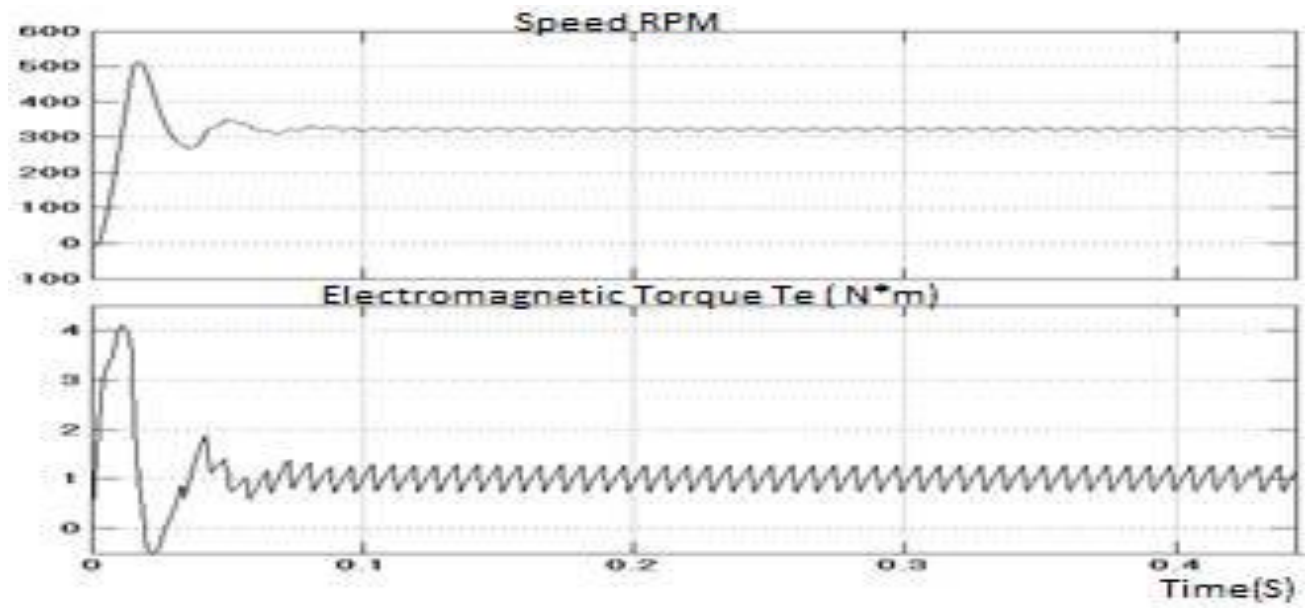

Figure 17 Speed (RPM) \& Torque (N-m)

It is known that speed and torque are inversion of each other which is shown in the figure 17 for the motor.

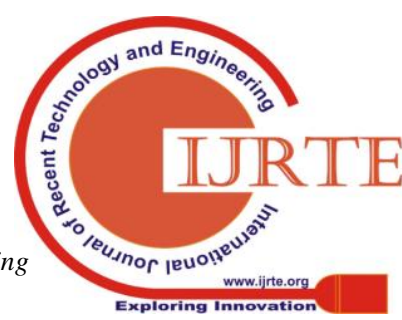




\section{HARDWARE AND RESULTS}

Table 2: Hardware specification

\begin{tabular}{|l|l|}
\hline \multicolumn{1}{|c|}{ Parameter } & \multicolumn{1}{c|}{ Specifications } \\
\hline Diode MUR 1640 & $300 \mathrm{~V}, 16 \mathrm{~A}$ \\
\hline MOSFET IRF250N & $200 \mathrm{~V}, 30 \mathrm{~A}$ \\
\hline Switching frequency $\left(\mathrm{f}_{\mathrm{S}}\right)$ & $40 \mathrm{KHZ}$ \\
\hline Inductor $\left(\mathrm{L}_{\mathrm{i}}\right)$ & $1 \mathrm{mH}, 10 \mathrm{~A}$ \\
\hline Capacitor $\left(\mathrm{C}_{\mathrm{j}}\right)$ & $45 \mu \mathrm{F}, 100 \mathrm{~V}$ \\
\hline Inductor $\left(\mathrm{L}_{\mathrm{o}}\right)$ & $185 \mu \mathrm{H}, 8 \mathrm{~A}$ \\
\hline Capacitor $\left(\mathrm{C}_{0}\right)$ & $6000 \mu \mathrm{F}, 63 \mathrm{~V}$ \\
\hline
\end{tabular}

Hardware Implementation of PFC cuk converter:

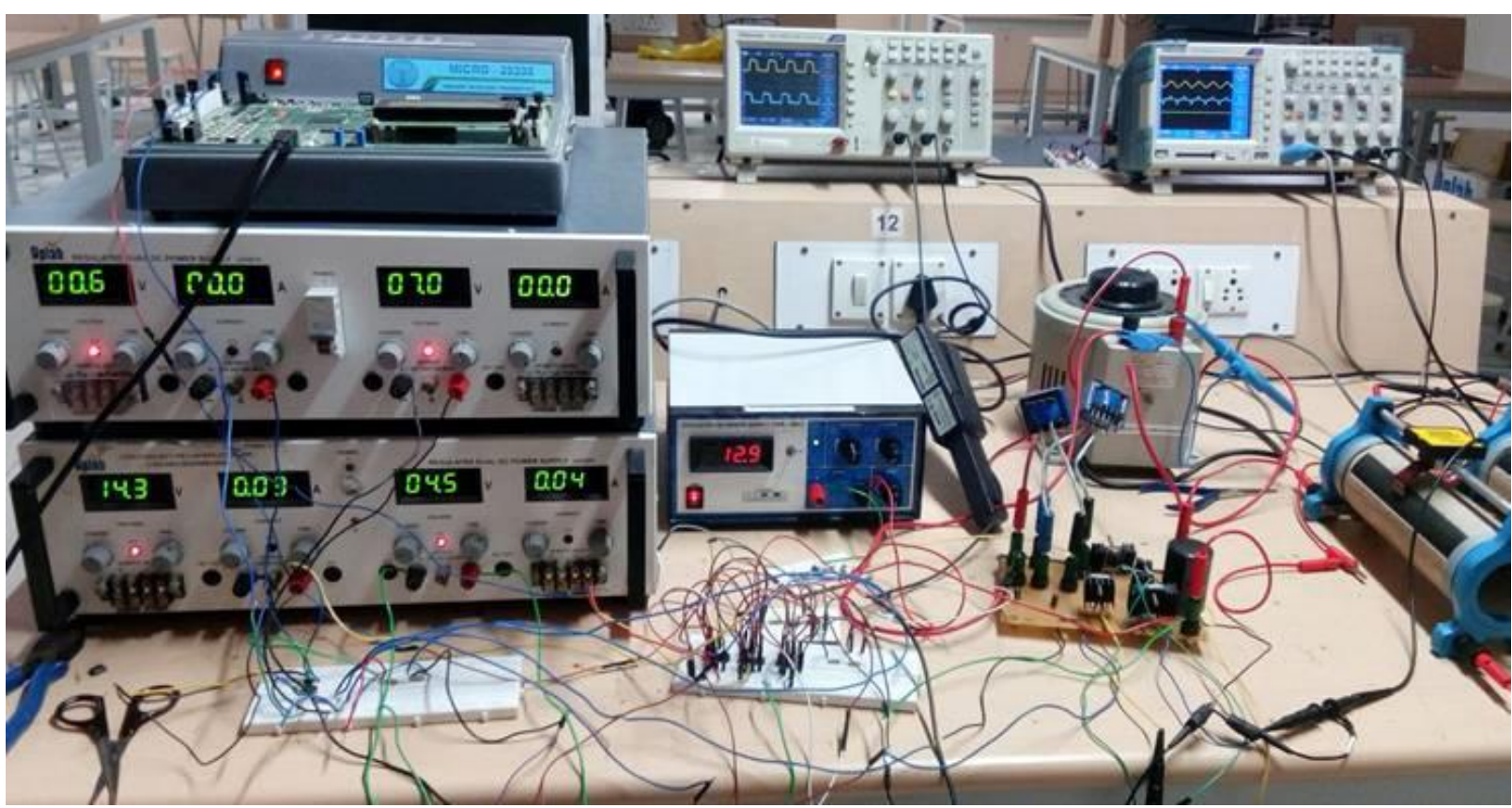

Figure 18: Investigational Setup of Cuk converter

In Figure 18, the converter is connected to a diode rectifier at the terminal of its input. A variac is used to supply AC Variable voltage. AC is converted into DC with the help of a Solid state DBR. A microcontroller which is an arduino Uno provides gate pulses for triggering to the MOSFET IRF250N.
Duty cycle is $34.5 \%$ and value of switching frequency is 40 $\mathrm{kHz}$. An IC named as IR1150S has been used in the implementation for different connections of converter to achieve a closed loop operation of it. Connections for this IC are given in figure 19.

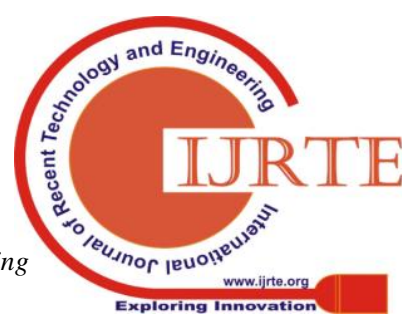




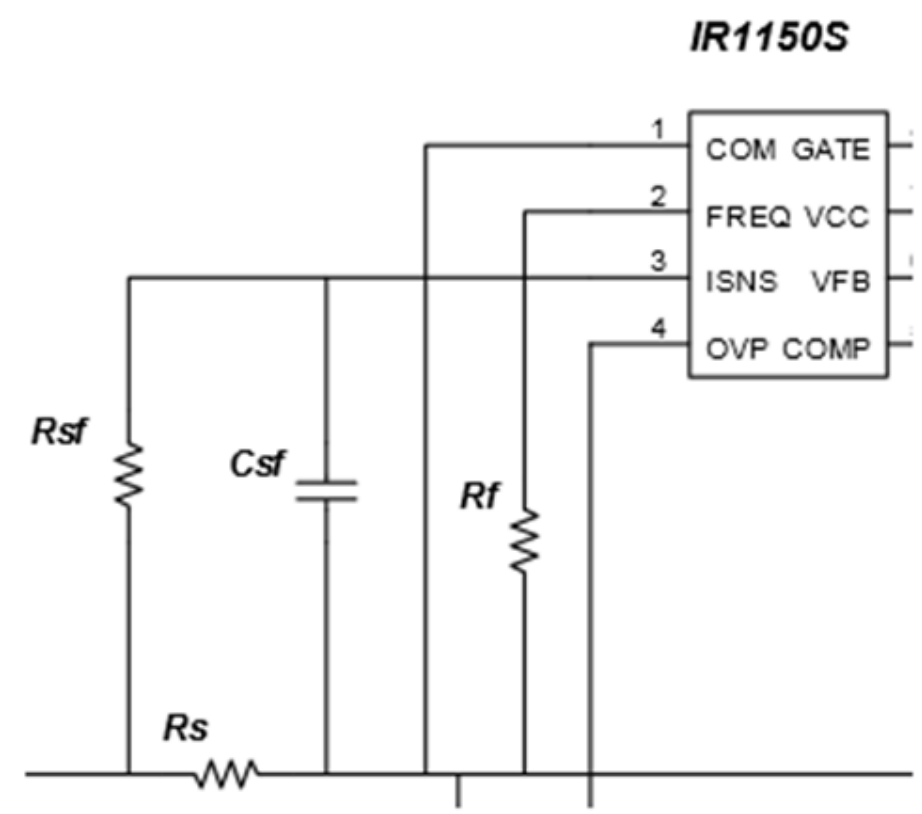

Figure 19 Closed Loop Used IC IR1150S

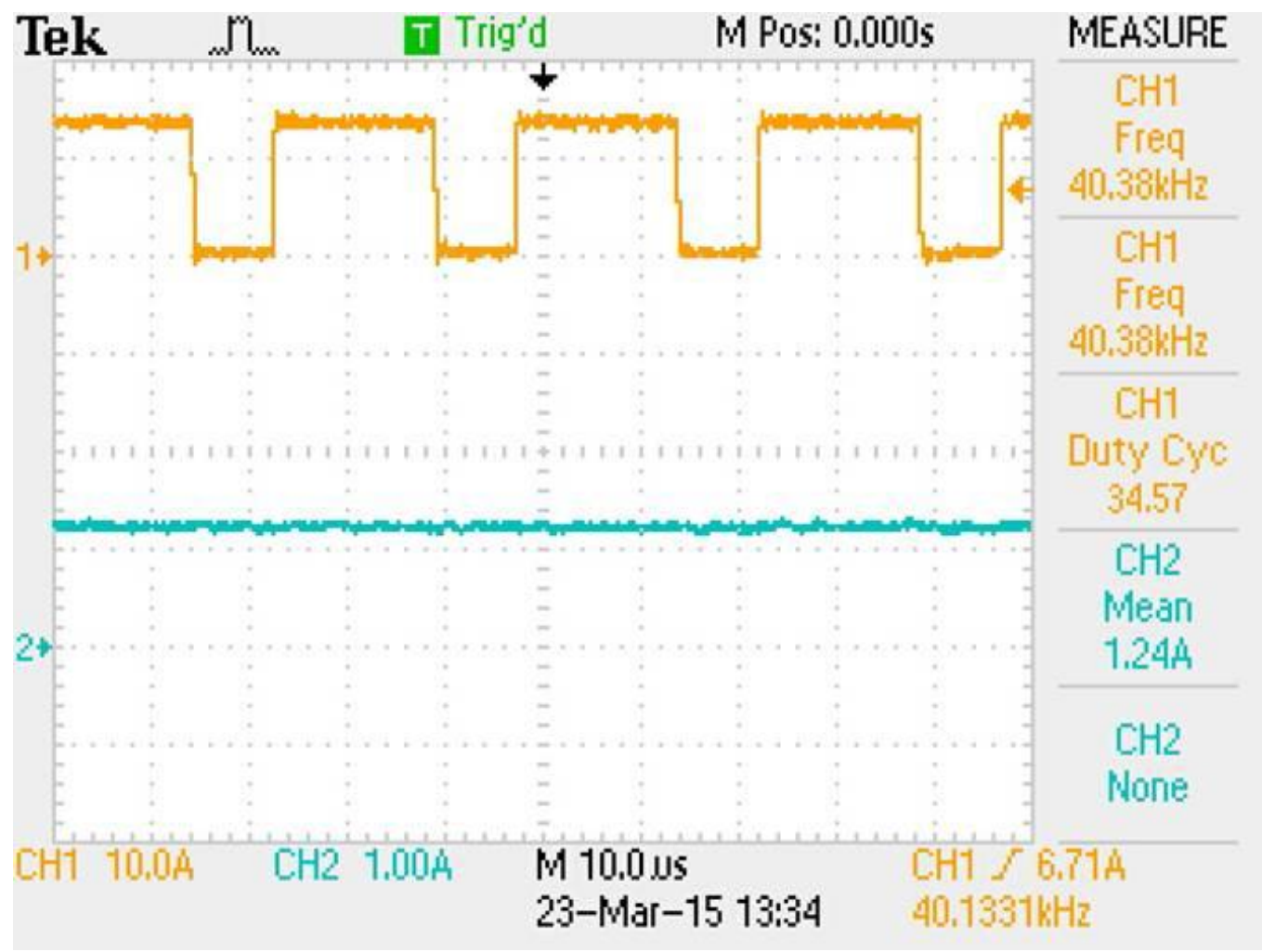

Figure 20 Gate pulse

$34.5 \%$ is the duty cycle as shown in Figure 20. 


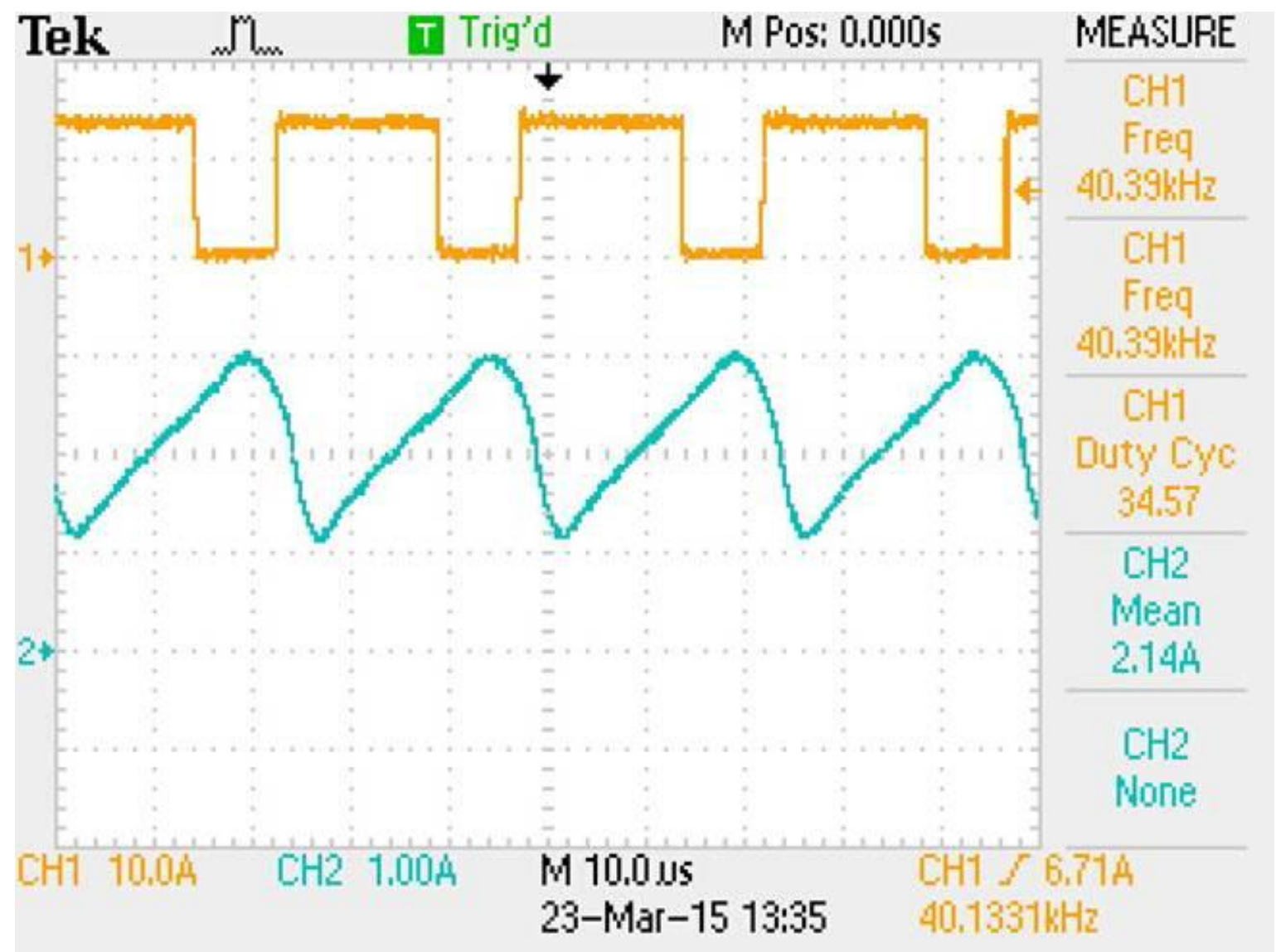

Figure 21 Input Inductor Current

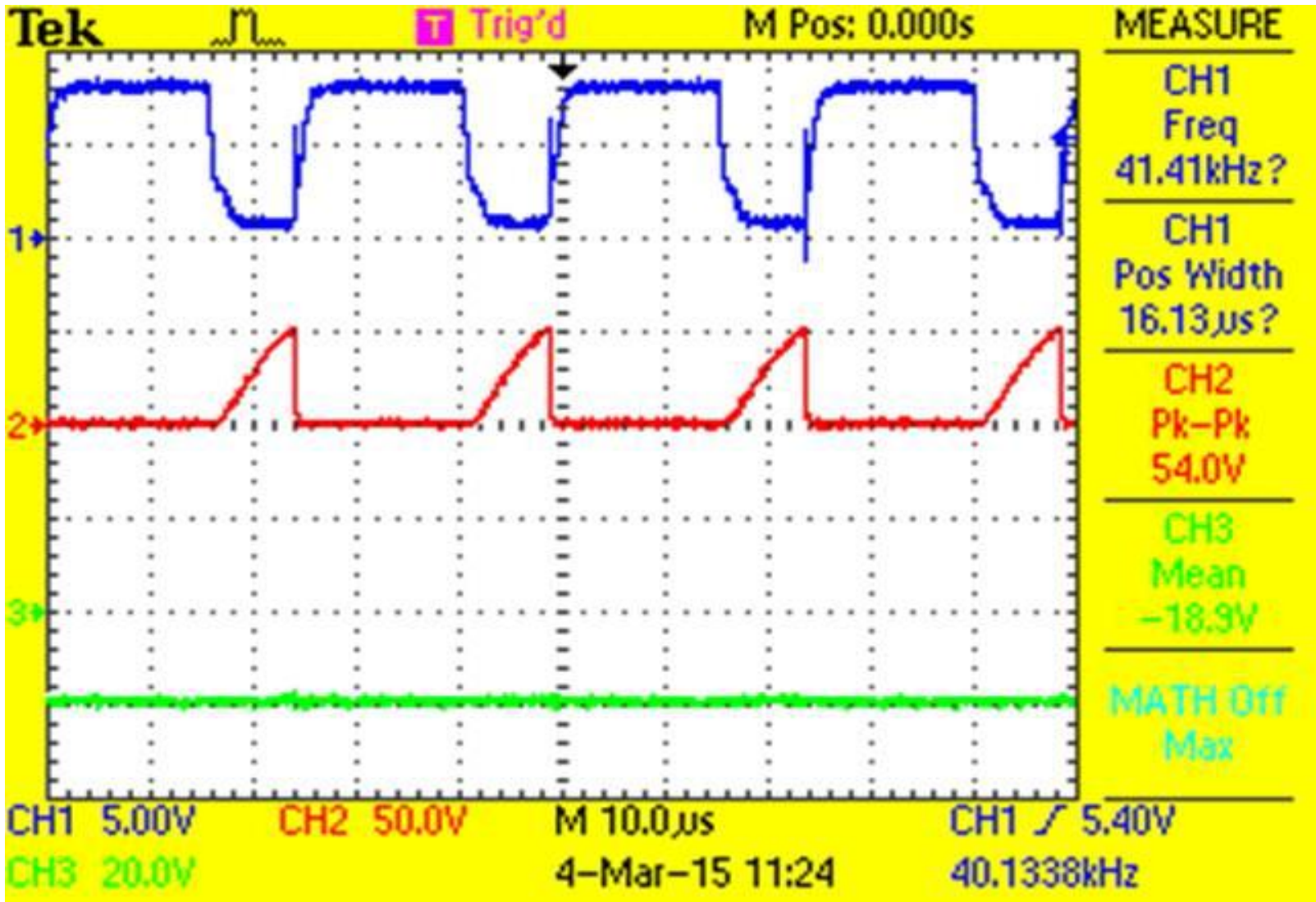

Figure 22 Switch Voltage

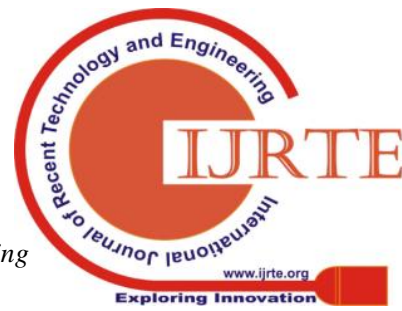




\section{DESIGN AND IMPLEMENTATION OF CUK CONVERTER FOR POWER FACTOR CORRECTION OF PMBLDC MOTOR DRIVE}

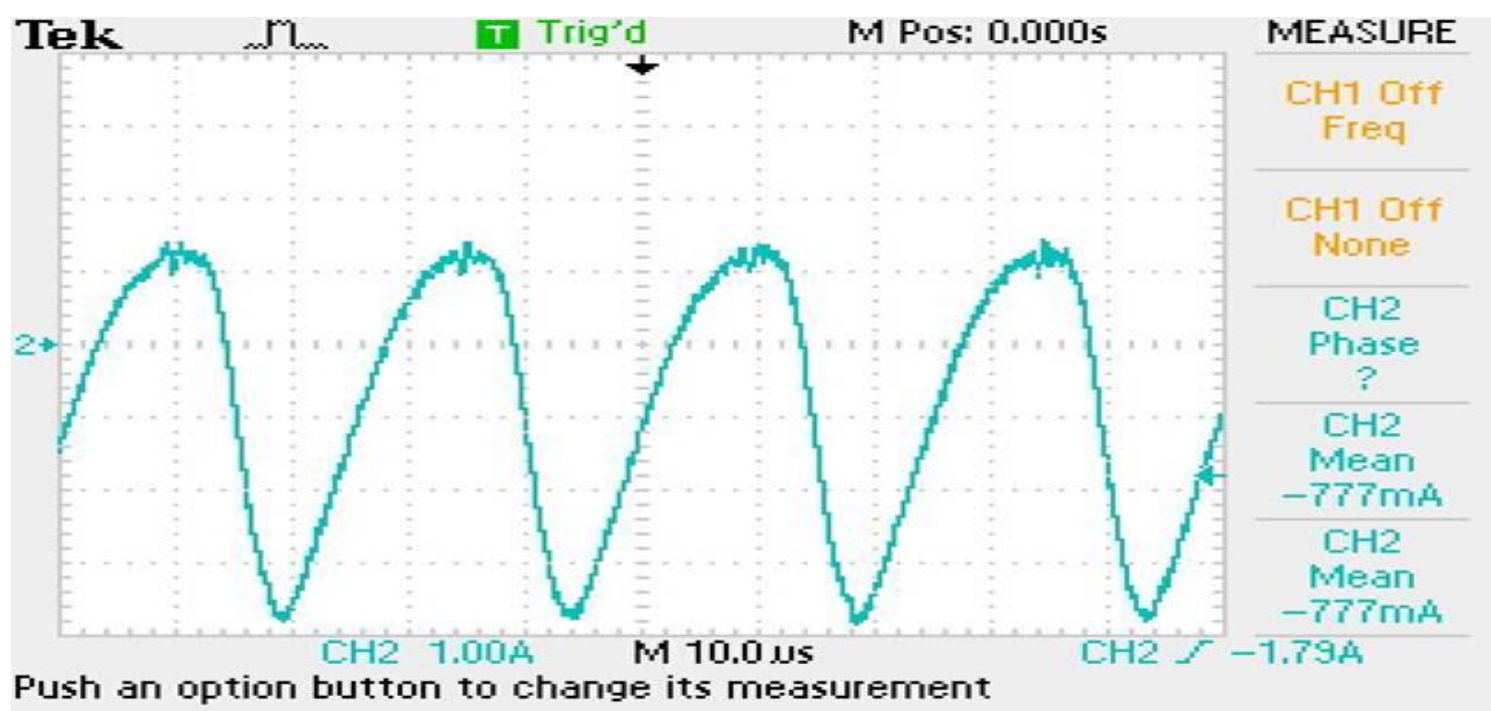

Figure 23 Output Inductor Current

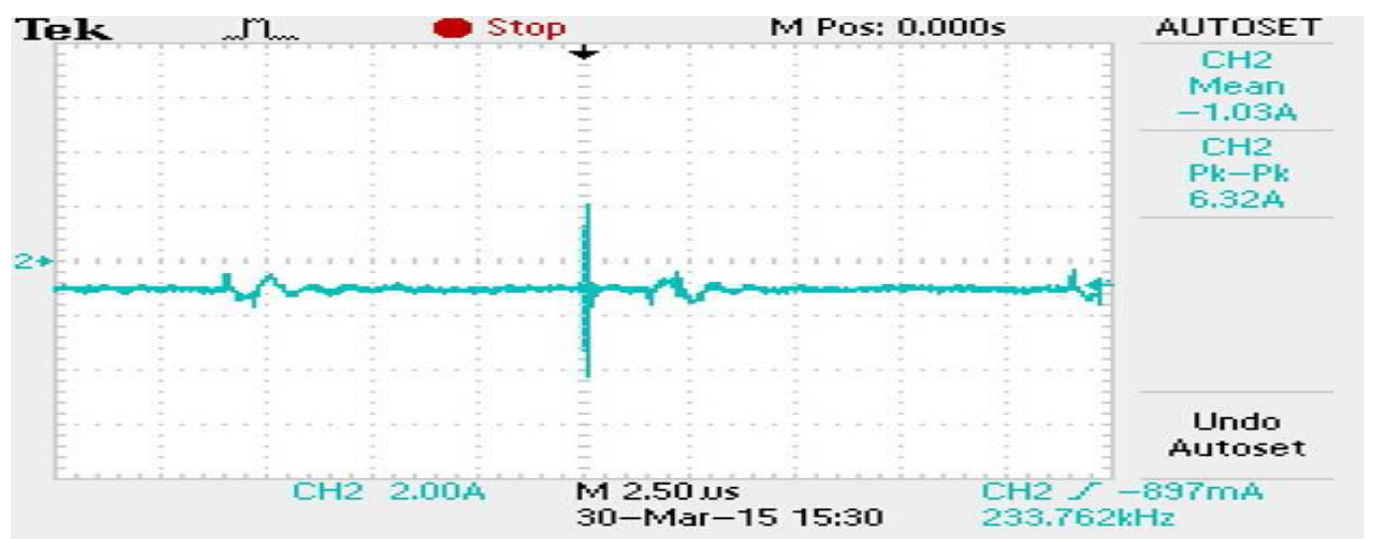

Figure 24 Output Current of the Cuk converter

From Figure 19 it can be seen that the input current value is 2.14A which linearly ups (to show charging behaviour) and downs (to show discharging behaviour). Figure 22 signifies the switching voltage which is applied by the variac AC power supply. By observing Figure 26 one can say that the voltage source inverter fed to the load motor having rating of $100 \mathrm{~W}$. The power rating of used voltage source inverter is 105 Watts that performs switching operation at $50 \mathrm{~Hz}$ line frequency.

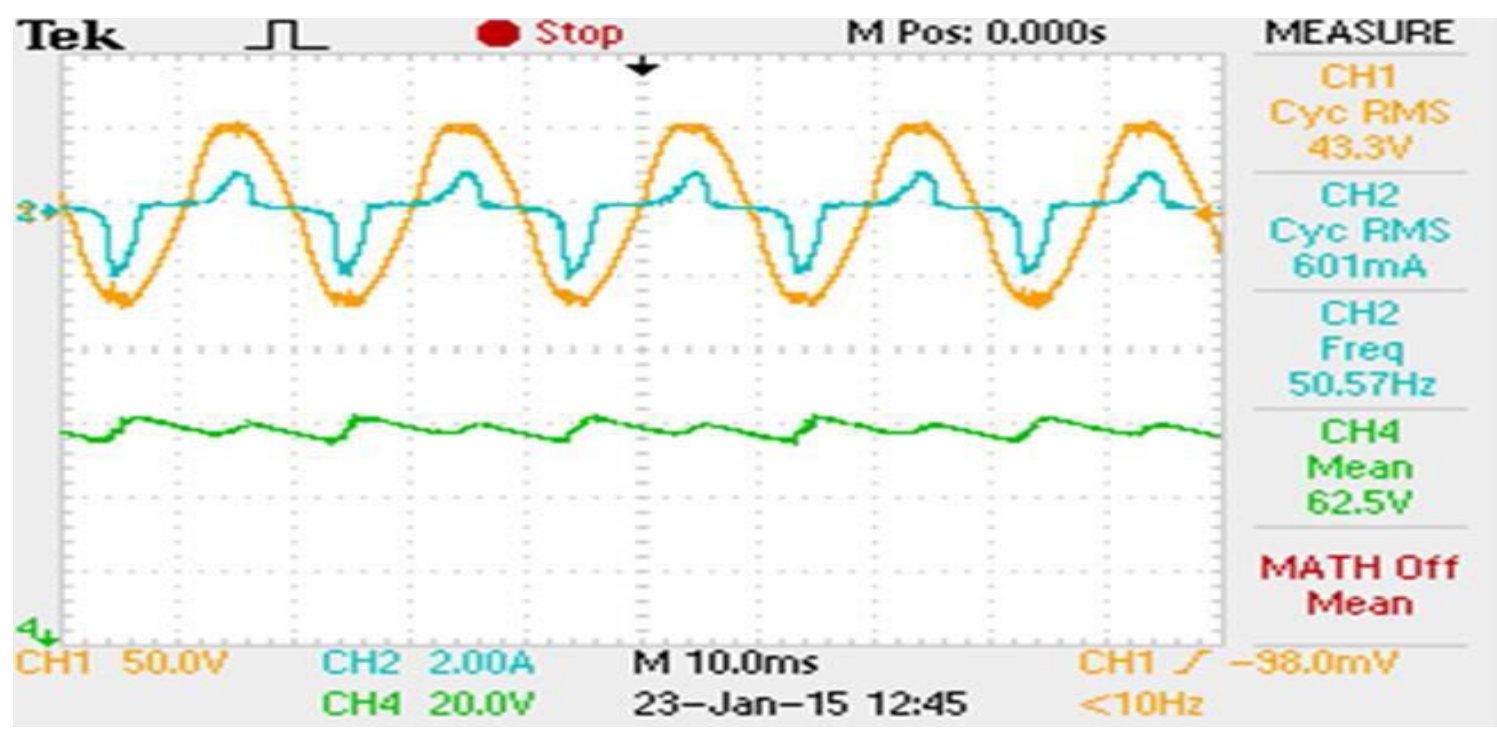

Figure 25 Closed Loop PFC at line frequency $50 \mathrm{~Hz}$ 


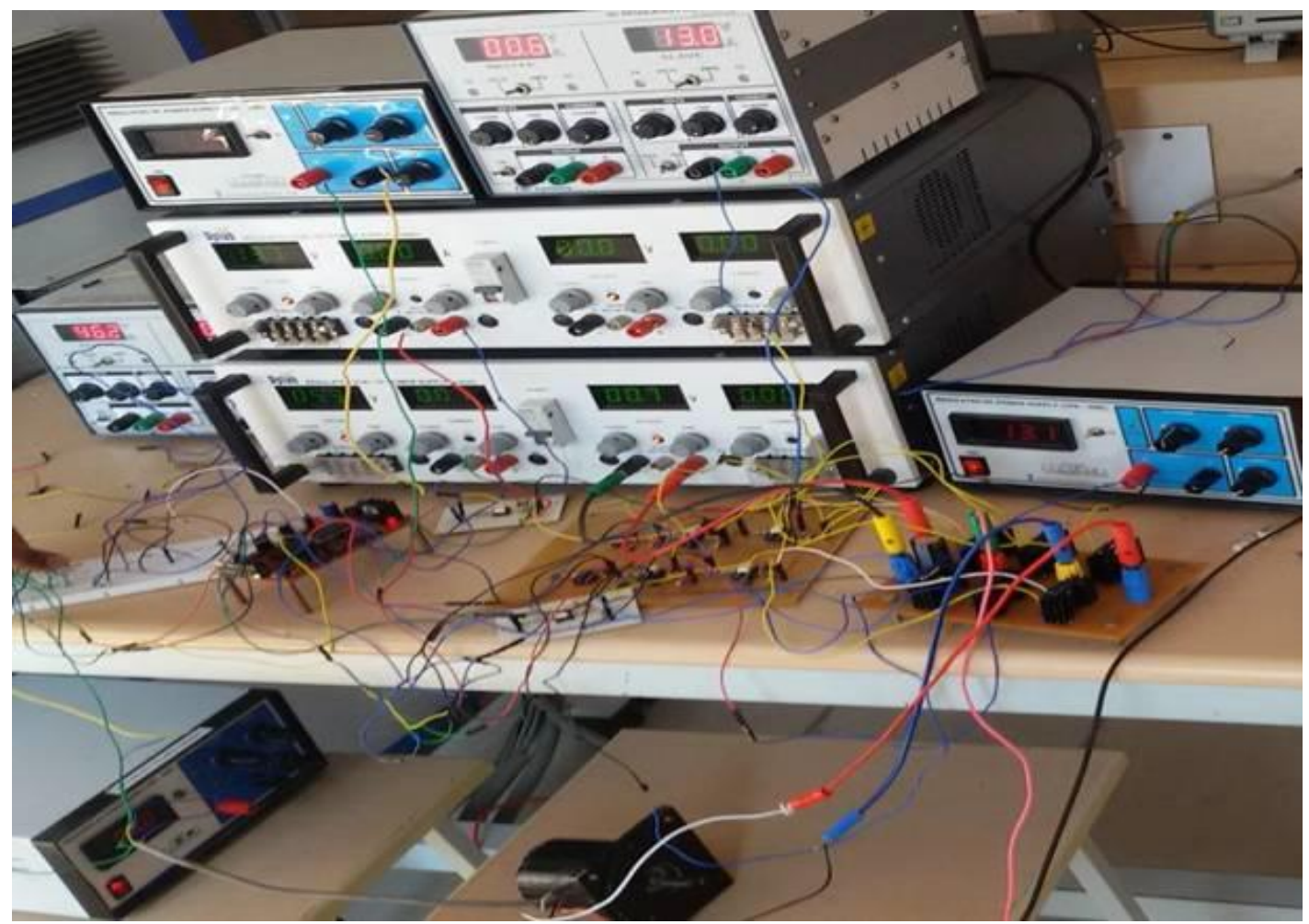

Figure 26 VSI Fed to BLDC Motor Drive

\section{CONCLUSION}

The 'cuk converter' for power factor improvement has been designed, tested and implemented effectively. The efficiency of the tested converter is about $92 \%$ which means it is providing an enhancive efficiency value for the betterment of power factor. It can be seen from the results section the power factor of the motor is improved by the strategy. Hardware results of proposed system are giving results within acceptable limit.

\section{REFERENCES}

1. V. Bist and B. Singh, "PFC Cuk converter-fed BLDC motor drive," IEEE Trans. Power Electron., 2015.

2. C. L. Xia, Permanent Magnet Brushless DC Motor Drives and Controls. 2012.

3. J. L. Kirtley, "Permanent Magnet ' Brushless DC ' Motors," Introduction to Power Systems - Class Notes Chapter 12. 2003.

4. S. V. Dhople, A. Davoudi, A. D. Domínguez-García, and P. L. Chapman, "A unified approach to reliability assessment of multiphase DC-DC converters in photovoltaic energy conversion systems," IEEE Trans. Power Electron., 2012.

5. P. Alaeinovin and J. Jatskevich, "Filtering of hall-sensor signals for improved operation of brushless DC motors," IEEE Trans. Energy Convers., 2012.

6. V. Vlatković, D. Borojević, and F. C. Lee, "Input filter design for power factor correction circuits," IEEE Trans. Power Electron., 1996.

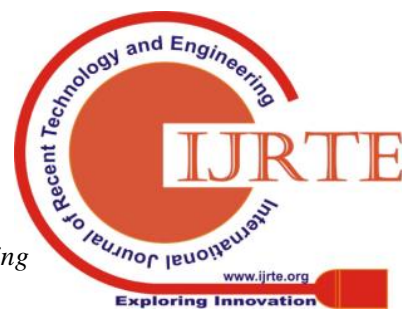

